\title{
A long-term Northern Hemisphere snow cover extent data record for climate studies and monitoring
}

\author{
T. W. Estilow ${ }^{1}$, A. H. Young ${ }^{2}$, and D. A. Robinson ${ }^{1}$ \\ ${ }^{1}$ Department of Geography, Rutgers, The State University of New Jersey, 54 Joyce Kilmer Ave, Piscataway, \\ NJ 08854, USA \\ ${ }^{2}$ NOAA's National Climatic Data Center (NCDC), 151 Patton Ave, Asheville, NC 28801, USA
}

Correspondence to: T. W. Estilow (thomas.estilow@ rutgers.edu)

Received: 30 September 2014 - Published in Earth Syst. Sci. Data Discuss.: 21 November 2014

Revised: 19 May 2015 - Accepted: 29 May 2015 - Published: 18 June 2015

\begin{abstract}
This paper describes the long-term, satellite-based visible snow cover extent National Oceanic and Atmospheric Administration (NOAA) climate data record (CDR) currently available for climate studies, monitoring, and model validation. This environmental data product is developed from weekly Northern Hemisphere snow cover extent data that have been digitized from snow cover maps onto a Cartesian grid draped over a polar stereographic projection. The data have a spatial resolution of $190.6 \mathrm{~km}$ at $60^{\circ}$ latitude, are updated monthly, and span the period from 4 October 1966 to the present. The data comprise the longest satellite-based CDR of any environmental variable. Access to the data is provided in Network Common Data Form (netCDF) and archived by NOAA's National Climatic Data Center (NCDC) under the satellite Climate Data Record Program (doi:10.7289/V5N014G9). The basic characteristics, history, and evolution of the data set are presented herein. In general, the CDR provides similar spatial and temporal variability to its widely used predecessor product. Key refinements included in the CDR improve the product's grid accuracy and documentation and bring metadata into compliance with current standards for climate data records.
\end{abstract}

\section{Introduction}

Annual and interannual variations in continental snow and sea ice extent are major factors in the earth-atmosphere energy balance and serve as key indicators of climate change (e.g., Cavalieri et al., 1997; Robinson et al., 1993; Robinson, 1997). Understanding their variability is critical to identify climate-cryosphere interactions known to be largely expressed via snow- and ice-albedo feedbacks. However, along with other cryospheric components, such as permafrost and land ice, other feedbacks that involve the regulation of soil moisture storage, latent heat flux, and the insulation of the underlying surface threaten Arctic and Antarctic ecosystem structure and stability (Stieglitz et al., 2003).

To evaluate cryospheric changes and their impacts, it is highly important to understand the data that are used for these critical investigations. The goal of this paper is to describe the National Oceanic and Atmospheric Administration (NOAA) Northern Hemisphere (NH) snow cover extent
(SCE) climate data record (CDR), which was recently added to NOAA's suite of cryospheric CDR products. This SCE CDR constitutes the longest running satellite-based record of any environmental variable. Even prior to its transition to a well-defined CDR product, its data have been used for a wide variety of regional-scale climate studies to evaluate spatial snow cover variability, climate and weather prediction models, changes in snow cover onset and retreat, and to diagnose trends in NH snow cover growth and decline. The SCE product has also been used in atmospheric teleconnection studies, analyses of snow cover feedbacks and surface albedo, and to estimate snow melt runoff (e.g., Mote and Kutney, 2012; Yang et al., 2009; Déry and Brown, 2007; Gong et al., 2007). Ongoing and future analyses will benefit from this more sophisticated data product.

To provide the SCE product in a more accessible format and make the documentation more transparent to users, these data were transitioned from research to operational produc- 
Table 1. Satellites and date of incorporation into snow mapping analysis for the NH SCE CDR. Primary platforms include the Environmental Science Services Administration (ESSA) series, NOAA Polar-orbiting Operational Environmental Satellites (POES), NOAA Geostationary Operational Environmental Satellites (GOES), the Defense Meteorological Satellite Program (DMSP) series, the Meteosat series, Geostationary Meteorological Satellites (GMS), Aqua, Terra, and the Multi-functional Transport Satellites (MTSAT).

\begin{tabular}{ll}
\hline Platform & First used for CDR \\
\hline ESSA & Oct 1966 \\
NOAA POES & Oct 1972 \\
NOAA GOES & May 1975 \\
DMSP & Jun 1977 \\
Meteosat & Feb 1988 \\
GMS & Jan 1989 \\
Aqua/Terra & Feb 2004 \\
MTSAT & Nov 2005 \\
\hline
\end{tabular}

tion per the guidelines of NOAA's CDR Program (CDRP, 2011a, b). The resulting CDR product has met all software, product validation, documentation, data archive, and access requirements by achieving sufficient maturity in both science and applications according to NCDC's CDR maturity matrix (Bates and Privette, 2012; Peng et al., 2013). This paper highlights various aspects of the NH SCE CDR, especially in relation to its historical beginnings, comparison with its predecessor product, data set description, access, applications, and its seasonal and spatial characteristics.

\section{Historical description of data product}

The NOAA visible satellite SCE product consists of weekly snow cover boundaries over Northern Hemisphere land surfaces, which are manually derived by trained meteorological analysts. Analysts use multiple satellite observations (Table 1), information from the previous snow cover map, and ancillary knowledge, such as surface elevation and vegetation, to create the snow cover product in a near-consistent manner without a formal algorithm. The high albedo of surface snow extent in visible-band satellite imagery makes delineation between snow-covered and snow-free land relatively simple over many land surfaces (Frei et al., 2011). Delineation of the seasonal snow line in areas with patchy snow or obscured by persistent cloud cover requires the use of the analyst's judgment. Thus, map quality relies on the expertise of the trained analyst and the availability of cloud-free visible satellite imagery (Ramsay, 1998). NOAA analysts have produced the SCE record in this manner for almost 5 decades and improvements to satellite instrumentation and variations in SCE mapping methods have occurred over time. While inconsistencies related to these changes cannot be fully eliminated, they are likely small compared to seasonal and interan-

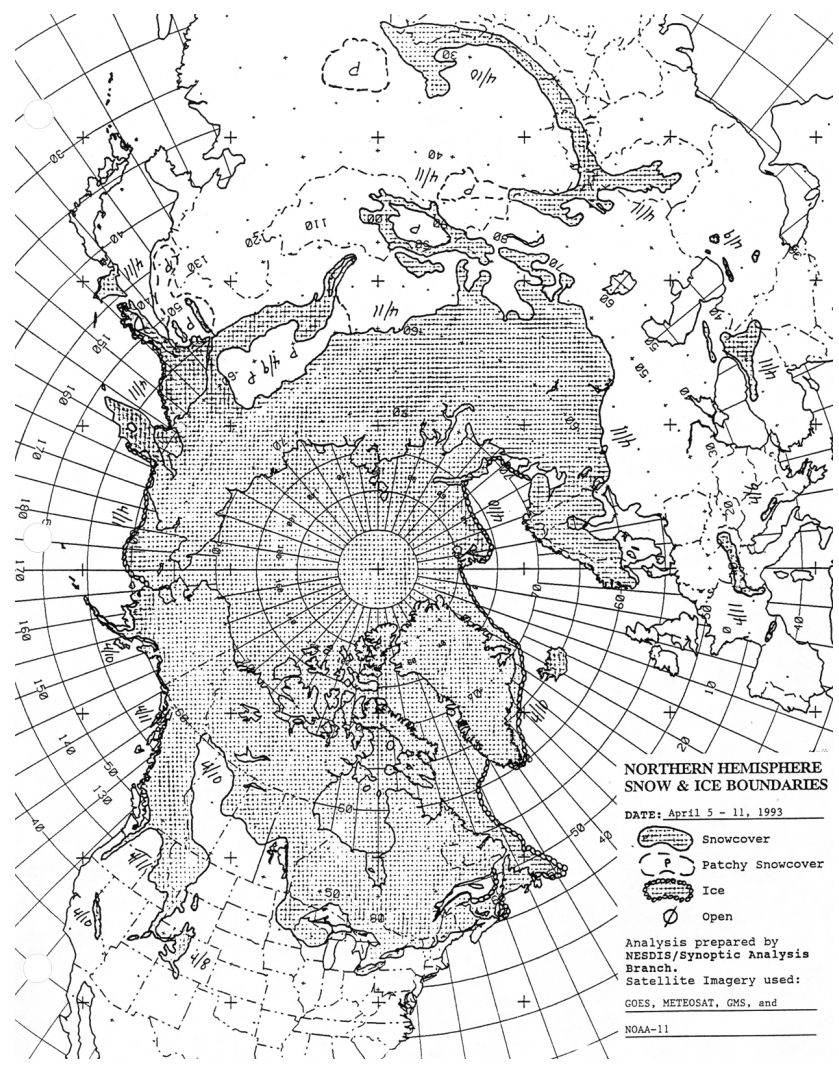

Figure 1. NOAA hand-drawn SCE analysis corresponding to week 15 of 1993.

nual variations in continental-scale SCE (Brown and Robinson, 2011).

The earliest part of the CDR time series begins in 1966 and is comprised of hand-drawn weekly SCE maps (Fig. 1) based on shortwave imagery from meteorological satellites with a subpoint resolution of $\sim 4 \mathrm{~km}$. These maps were operationally digitized onto an $89 \times 89$ Cartesian grid laid over an $\mathrm{NH}$ polar stereographic projection, and used in National Weather Service numerical forecasting models. Grid cells were designated as snow covered when $\geq 50 \%$ of their land surface was snow covered, resulting in a $190.6 \mathrm{~km}$ resolution binary (snow/no snow) mask.

After October 1972, SCE data production increasingly relied on satellite imagery from the Very High Resolution Radiometer (VHRR), which had a spatial resolution of $1.0 \mathrm{~km}$. The inclusion of higher-resolution data considerably improved snow charting (Kukla and Robinson, 1981). Over time, additional products utilized in the mapping of SCE included earth-observing satellite imagery from instruments such as the Advanced Very High Resolution Radiometer (AVHRR) and Visible Infrared Spin-Scan Radiometer (VISSR).

A land mask was developed to resolve inconsistencies found in the coastal land and sea mapping in digitized SCE maps produced by NOAA analysts (Robinson et al., 1993). 
This correction has been applied to the CDR time series and results in a consistent coastline for the entire period of record.

Each weekly map shows snow boundaries on the last day the land surface was observed in a given region (Robinson and Frei, 2000). Using this approach, weekly SCE maps are heavily weighted towards the end of the mapping week.

\subsection{Transition to daily snow charting}

In 1997, the National Ice Center (NIC) introduced the Interactive Multisensor Snow and Ice Mapping System (IMS). Inputs for IMS evolved to a more diverse set of products including satellite imagery, snow and ice analysis maps, National Centers for Environmental Prediction (NCEP) model data, and surface observations. Among these inputs, time sequenced satellite imagery improved the discrimination between snow and clouds following the assumption that any short-term changes in reflectance can only be introduced by clouds (Lyapustin et al., 2008; Gafurov and Bárdossy, 2009). Since its inception, the IMS has served as a more effective and modernized approach to snow mapping compared to the historical approach. Using the IMS tool, snow extent output has been produced at spatial and temporal resolutions corresponding to a $24 \mathrm{~km}$ daily product (Ramsay, 1998; Helfrich et al., 2007).

Both the historical weekly SCE maps and the higherresolution IMS products were independently produced during a 2-year overlap period from June 1997 to May 1999. To generate a pseudo-weekly product using daily IMS SCE (to ensure continuity in evaluating the full satellite-era snow extent record), it was necessary to compare the two independently produced versions generated during the overlap period. SCE area calculations performed with these data revealed that Monday IMS output best matched the corresponding weekly product output. A reduction in the $24 \mathrm{~km}$ IMS maps to $190.6 \mathrm{~km}$ resolution was also performed using a threshold to determine the location of SCE. To designate a weekly grid cell as snow covered, $\geq 42 \%$ of the IMS land pixels falling within the cell must indicate snow. This threshold provided the best match between weekly SCE areas and Monday IMS SCE areas during the overlap period. While a longer overlap period may have improved the analysis, the 2year sample provided by NOAA was invaluable to preserving continuity in the CDR time series.

Starting in June 1999 the CDR is completely derived in this manner, reducing the spatial resolution of IMS output to produce weekly granules conforming to the historical weekly SCE product. Although the IMS data used in this process are dated Monday, satellite imagery from the $36 \mathrm{~h}$ leading up to the analysis time can be used to more accurately delineate SCE boundaries (Robinson et al., 1999).

The transition from weekly to daily maps has not resulted in an artificial step change in spring continental-scale SCE (Brown and Robinson, 2011; Robinson et al., 1999). More research is needed to determine whether SCE analysis in mountainous regions (e.g., the Tibetan Plateau) shows systematic change during this time period. While there are differences in the production of the historical data compared with IMS, the conversion of IMS snow output to weekly SCE maps is automated and reproducible.

To date, the weekly SCE data product has been widely used by the cryospheric community. The CDR is an improved version of the data series, with efforts to achieve CDR status described in the following sections.

\section{Data set description}

The combination of both the historical and IMS-derived data records forms a continuous record of NH SCE that extends from October 1966 to the present. The CDR is a complete record with the exception of 9 months falling within the summer and fall seasons that are missing satellite imagery, namely July 1968, June-October 1969, and JulySeptember 1971.

Starting from the beginning of the record on Tuesday, 4 October 1966, each weekly CDR granule represents 7 days spanning from Tuesday to Monday. The primary CDR variable is SCE, which is provided as a binary value (snow/no snow) in each grid pixel. Ancillary variables are also provided, including pixel areas in square kilometres, pixel center point latitude and longitude coordinates, and a binary land mask (land/water).

\subsection{File format and metadata standards applied}

The weekly data are available in Network Common Data Form (netCDF), which is self-describing, platform independent, and archivable. All weekly CDR granules are stored in a single netCDF-4 file. Metadata elements comply with climate and forecast (CF-1.6) conventions, and collection-level metadata adheres to ISO 19115-2 standards for geographic information to facilitate data set discovery. These netCDF file metadata are structured following guidelines recommended by the NCDC satellite Climate Data Record Program (CDRP, 2011b).

\subsection{Definition of the CDR grid}

The latest CDR product includes refinements to the $\mathrm{NH}$ Cartesian grid previously distributed by NOAA's Satellite and Information Service. Cell center geographic coordinates were evaluated against a regular grid in polar stereographic coordinates (PSC) with a cell size of $190.6 \times 190.6 \mathrm{~km}$. The total calculated area of the two grids agreed within $-0.74 \%$ indicating that the grid provided by NOAA (B. Ramsay, personal communication, 1998) and released in an earlier version of the CDR slightly underestimates total area. Except for three grid cells located over the pole, the longitude and latitude coordinates were found to be accurate to within $\pm 26 \mathrm{~km}$, and cell areas were accurate to within $\pm 459 \mathrm{~km}^{2}$ (J. Biard, 


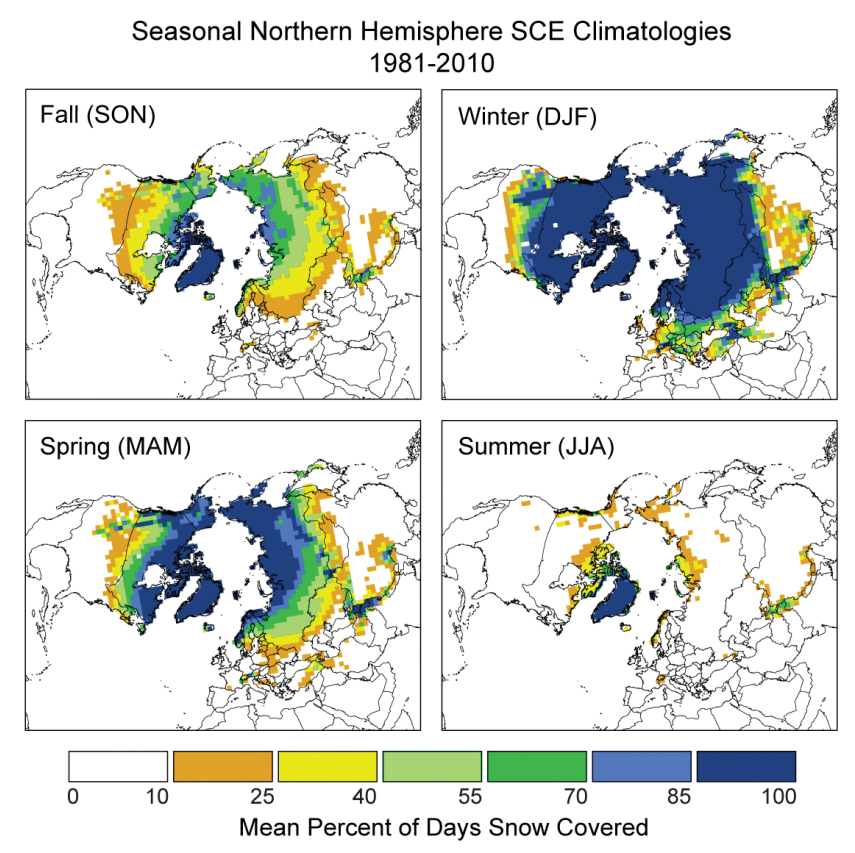

Figure 2. Mean spatial distribution of seasonal SCE over Northern Hemisphere lands. Each season is calculated using 3-month means. These maps illustrate seasonal variability, with maximum mean SCE occurring in winter. The data period used to calculate means spans the period from January 1981 to December 2010.

personal communication, 2012). All geographic coordinates and cell areas in the latest version of the CDR product have been corrected to correspond to the regular grid in PSC. These refinements do not impact the presence or absence of snow at these grid locations since the determination of snow is made in row and column space, not by latitude and longitude coordinates.

Cell areas range from $\sim 10700 \mathrm{~km}^{2}$ near the Equator to $\sim 41800 \mathrm{~km}^{2}$ near the pole. To generate the CDR, values from an $88 \times 88$ subset of the historical weekly $89 \times 89 \mathrm{SCE}$ matrices are used to populate the SCE variable in the netCDF-4 binary file. This allows the CDR product to provide data only for grid cells that lie entirely north of the Equator.

\section{Basic characterization of the CDR}

SCE area values for the full period of record have been calculated in a consistent manner at Rutgers University for over 2 decades using the Rutgers routine (Robinson et al., 1993). The area summation of all grid pixels that indicate snow in a given week generates the weekly snow cover extent for the entire Northern Hemisphere.

From the weekly data, monthly and seasonal maps can be produced. Figure 2 shows seasonal variability, with maximum mean SCE occurring in winter.
Table 2. NH SCE CDR monthly statistics (and year of max/min) in millions of square kilometres. Calculated using a data period spanning November 1966 to July 2014. Missing months (July 1968, June-October 1969, July-September 1971) are not included.

\begin{tabular}{lrrrr}
\hline Month & Mean & Max (year) & Min (year) & SD \\
\hline Jan & 47.09 & $50.28(2008)$ & $41.89(1981)$ & 1.57 \\
Feb & 46.07 & $51.32(1978)$ & $42.67(1995)$ & 1.84 \\
Mar & 40.62 & $44.28(1985)$ & $37.12(1990)$ & 1.82 \\
Apr & 30.57 & $34.61(1979)$ & $28.00(1968)$ & 1.69 \\
May & 19.34 & $23.09(1974)$ & $15.38(2010)$ & 1.93 \\
Jun & 9.80 & $14.97(1978)$ & $4.92(2012)$ & 2.34 \\
Jul & 4.06 & $8.21(1967)$ & $2.33(2012)$ & 1.24 \\
Aug & 3.03 & $5.31(1967)$ & $2.09(1968)$ & 0.74 \\
Sep & 5.32 & $7.76(1972)$ & $3.84(1990)$ & 0.93 \\
Oct & 18.08 & $25.72(1976)$ & $12.78(1988)$ & 2.54 \\
Nov & 33.91 & $38.60(1993)$ & $28.28(1979)$ & 2.04 \\
Dec & 43.68 & $46.85(2012)$ & $37.44(1980)$ & 1.93 \\
\hline
\end{tabular}

\subsection{Annual SCE variability}

Mean NH snow cover extent reaches its maximum in January and minimum in August, ramping up quickly in the fall and melting at a slower pace in the spring. The mean annual CDR SCE is 25.1 million $\mathrm{km}^{2}$, with a standard deviation (SD) of 0.9 million $\mathrm{km}^{2}$. Mean annual maximum SCE totals 47.4 million $\mathrm{km}^{2}(\mathrm{SD}=1.5)$, which is 44.4 million $\mathrm{km}^{2}$ more extensive than the mean annual minimum of 3.0 million $\mathrm{km}^{2}$ $(\mathrm{SD}=0.7)$. The highest annual maximum SCE occurred in February 1978, totaling 51.3 million $\mathrm{km}^{2}$. At the opposite end of the rankings, the lowest annual minimum SCE of 2.1 million $\mathrm{km}^{2}$ was observed in August 1968 (Table 2).

The CDR shows 1978 as the snowiest year (i.e., September 1977 to August 1978), with an annual mean SCE of 27.2 million $\mathrm{km}^{2}$. In contrast, annual mean SCE in 1989 was the lowest, totaling 23.5 million $\mathrm{km}^{2}$. During the most recent 27 years of the CDR, mean annual SCE has continued to exhibit lower snow extents relative to the data period ending in mid-1987. This step change in NH SCE was first identified by Robinson and Dewey (1990).

\subsection{Long-term trends apparent in CDR snow extent}

Seasonal trends observed in the CDR include a pronounced decline in SCE during the spring melt season (Fig. 3). Fall and winter show an opposite trend towards increased extent, with winter SCE growing 0.19 million $\mathrm{km}^{2}$ per decade. Fall seasonal SCE means have increased by $0.26 \mathrm{~km}^{2}$ per decade. By contrast, spring SCE has decreased by -0.58 million $\mathrm{km}^{2}$ per decade, declining at 3 times the pace of the winter trend. This has also left the summer season with less snow on the ground, with summer SCE decreasing by -0.81 million $\mathrm{km}^{2}$ per decade.

Brown and Derksen (2013) found that over Eurasia the positive trend in fall SCE is internal to the CDR and is likely 

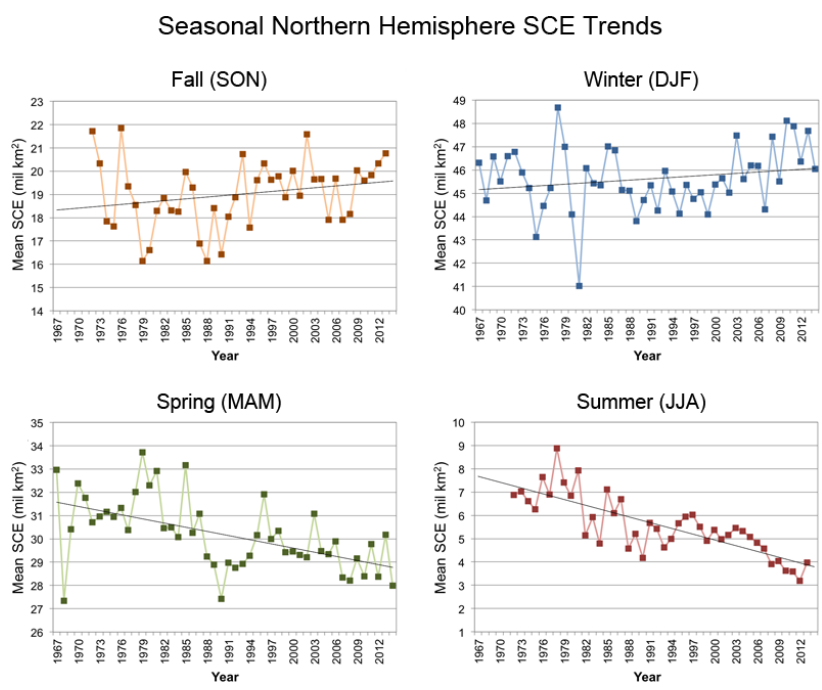

Figure 3. Seasonal SCE areas and linear least squares trends for the Northern Hemisphere in millions of square kilometres. Each season is calculated using 3-month means. Summer and fall are calculated from June 1972 onwards, due to missing months in the years 19681969 and 1971. No winter or spring months are missing.

a result of improved snow detection during the October snow onset period. SCE observations from other sources compared in the study exhibit a reduction in October SCE from 1982 to 2011, which is consistent with warming fall surface temperatures observed during this period.

Conversely, the negative trend in spring SCE shown by the CDR has been corroborated using observations from multiple independent data sources (Brown et al., 2010; Brown and Robinson, 2011). While the data sets show different areas of Arctic SCE, all data sources including the CDR exhibit similar SCE anomalies, which indicate significant reductions in Arctic SCE over the period 1967-2008.

Brown and Robinson (2011) derived estimates of uncertainty through the statistical analysis and comparison of multiple SCE data sources. The results indicate that the $95 \%$ confidence interval in March and April continental SCE is $\pm 3-5 \%$ during the satellite era beginning in 1967. The analysis also shows larger uncertainties in spring SCE monitoring over Eurasia compared to North America, in part due to larger variability between data sources over northern Europe and north-central Russia.

The CDR excels at portraying regional SCE in areas with high illumination, stable snow cover, and frequently clear skies. Despite the CDR's general homogeneity, difficulties in historical SCE charting over the Tibetan Plateau due to frequent cloud cover resembling patchy snow on the surface have resulted in higher uncertainty over this region. Positive biases have been shown in SCE mapping during summer months in the Canadian Arctic; this also relates to frequent cloud cover over the area (Wang et al., 2005; Brown et al., 2007).

\section{Conclusions}

A long-term, satellite-based visible snow cover extent CDR is currently available for climate studies, monitoring, and model validation. The CDR is provided in netCDF format with CF-1.6 compliant metadata. Trends and spatial variability are consistent with the predecessor NOAA weekly SCE product. Version 1 revision 1 provides improved grid accuracy and an $88 \times 88$ subset of pixels falling entirely within the NH. CDR documentation and product traceability meet current guidelines for climate data records. The generation of the weekly CDR from June 1999 onwards using the NIC IMS snow output is reproducible.

The CDR is a foundational product, used in other data products such as the Northern Hemisphere EASE-Grid 2.0 Weekly Snow Cover and Sea Ice Extent, Version 4, available at the National Snow and Ice Data Center (NSIDC). Two data products from the NASA Making Earth System Data Records for Use in Research Environments (MEaSUREs) program also incorporate the CDR: MEaSUREs Northern Hemisphere Terrestrial Snow Cover Extent Weekly $100 \mathrm{~km}$ EASE-Grid 2.0, and MEaSUREs Northern Hemisphere State of Cryosphere Weekly $100 \mathrm{~km}$ EASE-Grid 2.0 both published at NSIDC. Due to its relatively coarse spatial resolution, the CDR remains best suited for continental-scale and large regional studies.

IMS version 3 will incorporate additional upgrades to analyst workstations and snow output (S. Helfrich, personal communication, 2014). As SCE inputs continue to evolve, the need to ensure the ongoing homogeneity of these data records is critical to the identification and tracking of changes in this part of the cryosphere. Future improvements to the CDR will seek to increase product maturity according to NCDC's CDR Maturity Matrix and may include source code or metadata optimizations as well as additional validation work.

\section{Data set availability}

The NOAA climate data record of Northern Hemisphere snow cover extent, Version 1, is archived and distributed by NCDC's satellite Climate Data Record Program. The CDR can be downloaded via FTP or from the NCDC THREDDS data server (doi:10.7289/V5N014G9). The CDR is forward processed operationally every month, along with figures and tables made available at the website http://climate.rutgers. edu/snowcover/. 
Acknowledgements. The NOAA/NCDC Climate Data Record Program funded this project. The authors wish to thank D. Wunder, H. Brown, C. Hutchins, S. Ansari, R. McFadden and the entire Snow Cover Integrated Product Team (IPT) at NCDC for supporting the Research to Operations (R2O) process. Special appreciation goes to J. Biard for his review of the CDR and technical assistance with reprocessing the NOAA grid and to R. Brown whose helpful comments improved this manuscript.

Edited by: D. Carlson

\section{References}

Bates, J. J. and Privette, J. L.: A maturity model for assessing the completeness of climate data records, EOS T. Am. Geophys. Un., 93, p. 441, doi:10.1029/2012EO440006, 2012.

Brown, R., Derksen, C., and Wang, L.: Assessment of spring snow cover duration variability over northern Canada from satellite datasets, Remote Sens. Environ., 111, 367-381, doi:10.1016/j.rse.2006.09.035, 2007.

Brown, R., Derksen, C., and Wang, L.: A multi-data set analysis of variability and change in Arctic spring snow cover extent, 1967-2008, J. Geophys. Res., 115, D16111, doi:10.1029/2010JD013975, 2010.

Brown, R. D. and Derksen, C.: Is Eurasian October snow cover extent increasing?, Environ. Res. Lett., 8, 024006, doi:10.1088/1748-9326/8/2/024006, 2013.

Brown, R. D. and Robinson, D. A.: Northern Hemisphere spring snow cover variability and change over 1922-2010 including an assessment of uncertainty, The Cryosphere, 5, 219-229, doi:10.5194/tc-5-219-2011, 2011.

Cavalieri, D. J., Glowersen, P., Parkinson, C. L., Comiso, J. C., and Zwally, H. J.: Observed hemispheric asymmetry in global sea ice changes, Science, 278, 1104-1106, 1997.

Climate Data Record Program (CDRP): NetCDF Metadata Guidelines for IOC NOAA Climate Data Records, NOAA's NCDC CDR Program, CDRP-GUID-0042, Asheville, North Carolina, USA, 22 pp., 2011 a.

Climate Data Record Program (CDRP): Transitioning CDRs from Research to Operations, NOAA's NCDC CDR Program, CDRPPLAN-0017, Asheville, North Carolina, USA, 28 pp., $2011 b$.

Déry, S. J. and Brown, R. D.: Recent Northern Hemisphere snow cover extent trends and implications for the snow-albedo feedback, Geophys. Res. Lett., 34, L22504, doi:10.1029/2007GL031474, 2007.

Frei, A., Tedesco, M., Lee, S., Foster, J., Hall, D. K., Kelly, R., and Robinson, D. A.: A review of global satellitederived snow products, Adv. Space Res., 50, 1007-1029, doi:10.1016/j.asr.2011.12.021, 2011.

Gafurov, A. and Bárdossy, A.: Cloud removal methodology from MODIS snow cover product, Hydrol. Earth Syst. Sci., 13, 13611373, doi:10.5194/hess-13-1361-2009, 2009.
Gong, G., Cohen J., Entekhabi, D., and Ge, Y.: Hemispheric-scale climate response to Northern Eurasia land surface characteristics and snow anomalies, Global Planet. Change, 56, 359-370, doi:10.1016/j.gloplacha.2006.07.025, 2007.

Helfrich, S. R., McNamara, D., Ramsay, B. H., Baldwin, T., and Kasheta, T.: Enhancements to, and forthcoming developments in the Interactive Multisensor Snow and Ice Mapping System (IMS), Hydrol. Process., 21, 1576-1586, doi:10.1002/hyp.6720, 2007.

Kukla, G. and Robinson, D. A.: Accuracy of snow and ice monitoring, Snow Watch 1980, Glaciological Data, Report GD-5, 91-97, 1981.

Lyapustin, A., Wang, Y., and Frey, R.: An Automatic Cloud Mask Algorithm Based on Time Series of MODIS Measurements, J. Geophys. Res., 113, D16207, doi:10.1029/2007JD009641, 2008.

Mote, T. L. and Kutney, E. R.: Regions of autumn Eurasian snow cover and associations with North American winter temperatures, Int. J. Climatol., 32, 1164-1177, doi:10.1002/joc.2341, 2012.

Peng, G., Meier, W. N., Scott, D. J., and Savoie, M. H.: A long-term and reproducible passive microwave sea ice concentration data record for climate studies and monitoring, Earth Syst. Sci. Data, 5, 311-318, doi:10.5194/essd-5-311-2013, 2013.

Ramsay, B. H.: The interactive multisensor snow and ice mapping system, Hydrol. Process., 12, 1537-1546, doi:10.1002/(SICI)1099-1085(199808/09)12:10/11<1537::AIDHYP679>3.0.CO;2-A, 1998.

Robinson, D. A.: Hemispheric snow cover and surface albedo for model validation, Ann. Glaciol., 25, 241-245, 1997.

Robinson, D. A. and Dewey, K. F.: Recent secular variations in the extent of Northern Hemisphere snow cover, Geophys. Res. Lett., 17, 1557-1560, 1990.

Robinson, D. A. and Frei, A.: Seasonal variability of Northern Hemisphere snow extent using visible satellite data, Prof. Geogr., 52, 307-315, 2000.

Robinson, D. A., Dewey, F., and Heim Jr., R.: Global Snow Cover Monitoring: An update, B. Am. Meteorol. Soc., 74, 1689-1696, 1993.

Robinson, D. A., Tarpley, J. D., and Ramsay, B.: Transition from NOAA weekly to daily hemispheric snow charts. Proceedings of the 10th Symposium on Global Change, Dallas, TX, Am. Meteorol. Soc., 487-490, 1999.

Stieglitz, M., Déry, S. J., Romanovsky, V. E., and Osterkamp, T. E.: The role of snow cover in the warming of arctic permafrost, Geophys. Res. Lett., 30, 1721, doi:10.1029/2003GL017337, 2003.

Wang, L., Sharp, M., Brown, R., Derksen, C., and Rivard, B.: Evaluation of spring snow covered area depletion in the Canadian Arctic from NOAA snow charts, Remote Sensing of Environment, 95, 453-463, doi:10.1016/j.rse.2005.01.006, 2005.

Yang, D., Zhao, Y., Armstrong, R., and Robinson, D. A.: Yukon River streamflow response to seasonal snow cover changes, Hydrol. Process., 23, 109-121, doi:10.1002/hyp.7216, 2009. 